\title{
HOMOGENEIDADE E HETEROGENEIDADE NOS SISTEMAS EDUCACIONAIS: ARGENTINA, BRASIL, CHILE E MÉXICO
}

\author{
NORA RUT KRAWCZYK \\ Faculdade de Educação da Universidade Estadual de Campinas \\ norak@unicamp.br
}

VERA LÚCIA VIEIRA

Departamento de História da Faculdade de Ciências Sociais da Pontifícia Universidade

Católica de São Paulo

vevi@terra.com.br.

\begin{abstract}
RESUMO
O estudo focaliza a reconfiguração da gestão educacional a partir da nova lógica de regulação social e do novo papel do Estado, à luz da historicidade dos países estudados (Argentina, Brasil, Chile e México), examinando os fatores culturais que interferiram na dinâmica da reforma educacional da década de 90. Aspectos que evidenciam a homogeneidade e a heterogeneidade dessa reforma na região, bem como as especificidades nacionais que intervieram em sua concretização, são destacados. Afirma que a historicidade que caracteriza a realidade educacional tem sofrido, no México, o que poderíamos denominar "ruptura conservadora"; no Chile, "continuidade conservadora"; no Brasil, "renovação conservadora"; e, na Argentina, "ruptura interrompida". Recupera algumas conclusões alcançadas por meio da análise de 186 textos de caráter acadêmico sobre os impactos, nos países estudados, da reforma educacional da década.

SISTEMA DE EDUCAÇÃO - REFORMA DO ENSINO - ARGENTINA - BRASIL - CHILEMÉXICO
\end{abstract}

\section{ABSTRACT}

HOMOGENEITY AND HETEROGENEITY ON EDUCATION SYSTEMS IN ARGENTINE, BRAZIL, CHILE AND MEXICO. This study focus on the reconfiguration of educational management in Argentina, Brazil, Chile and Mexico, which was promoted by the new logic of social regulation and the new role attributed to the State, considering each country's own historicity. So, the cultural factors that interfere on the dynamics of the 90' school reform are analyzed. Aspects that show the homogeneity or heterogeneity of these reforms in the region, as well as local specificities that block out the concretization of the reform are underlined. It is shown that the historicity that characterizes the educational reform has taken, in each country, 
a form that can be called, in Mexico, "conservative rupture"; in Chile, "conservative continuity"; in Brazil, "conservative renovation"; and, in Argentina, "interrupted rupture". Some conclusions about the impact of educational reform in the selected countries are recuperated through the analysis of 186 academic texts on the subject.

EDUCATION SYSTEMS - EDUCATIONAL REFORM - ARGENTINA - BRAZIL - CHILE - MEXICO

Na década de 90 iniciaram-se, na América Latina, reformas educacionais no bojo de transformações profundas nas esferas da economia, das instituições sociais, culturais e políticas - bem como na natureza das relações entre essas diferentes esferas. Elas tiveram como finalidade não só a expansão do ensino, mas também a adequação da educação pública às mudanças da lógica de regulação capitalista.

Em quase todos os países essas reformas foram resultantes, em grande medida, de um processo de indução externa, articulado com as políticas de organismos internacionais de empréstimo para a região. A necessidade das reformas foi justificada mediante a publicação de pesquisas que evidenciaram os sucessos e deficiências dos sistemas educacionais à luz dos condicionantes da reestruturação do setor produtivo e das mudanças institucionais que alteraram a estrutura do Estado e das relações sociais, no âmbito de uma nova ordem mundial.

Nesses estudos se indicava que o crescimento da matrícula escolar na região, durante os anos 60, ocorreu concomitantemente à diminuição da qualidade do sistema, mais aguda ainda nos anos 80. A ausência da gestão do orçamento, de uma organização institucional adequada e de uma proposta pedagógica acorde com a heterogeneidade sociocultural da população incorporada pela escola teria produzido a ineficácia do sistema para responder às necessidades próprias do capitalismo nesse momento histórico.

O diagnóstico e as mudanças propostas para a educação na América Latina no período foram elaborados a partir das necessidades de reformulação do caráter regulador do Estado e da forte crítica às funções dos Estados nacionais de modelo keynesiano, no marco de um novo estágio do capitalismo.

Passados dez anos da implementação da reforma, as pesquisas efetuadas pelos especialistas nos diferentes países mostram o fracasso das promessas que seus ideólogos fizeram à sociedade. Também fica claro, nesses estudos, que a 
uniformidade das políticas de educação, em escala global, está vinculada ao crescente peso das agências internacionais e da liderança do Banco Mundial no desenho e na execução da reforma educacional nos países em desenvolvimento.

$O$ conjunto das pesquisas evidencia que as reformas têm um caráter homogêneo e homogeneizador - tanto na compreensão das realidades nacionais quanto em suas propostas, padronizando a política educacional na região. Quando se reflete sobre os aspectos das condições de desenvolvimento particular dos países, entretanto, observa-se que as reformas se processam em sociedades com histórias distintas que, de alguma forma, intervêm na concretização das mudanças, o que lhes conferiria especificidades nacionais. Isso não invalida o fato de que a reforma educacional tenha produzido rupturas institucionais que fragilizam práticas sociais historicamente constituídas.

$O$ estudo das realidades nacionais a partir de uma perspectiva analítica e explicativa possibilita compreender a historicidade das categorias de análise nos diferentes países e desentranhar a interpenetração que se dá entre os níveis locais e global, reestruturando as culturas institucionais. Esse propósito nos levou à análise das pesquisas sobre a reforma educacional na década de 90 na Argentina, no Chile, no Brasil e no México e a realizar um estado da arte para compreender as características da produção do conhecimento em cada um desses países e as especificidades na concretização da reforma (Krawczyk; Vieira, 2005)'.

Neste artigo analisaremos, nos processos de transformação ocorridos nesses países, as mudanças na organicidade do sistema educacional que homogeneizam as situações nacionais, assim como suas particularidades. Entendemos como organicidade a dinâmica pela qual se processam as relações de poder na organização e gestão do sistema educacional e da unidade escolar. Carrega esse conceito a historicidade das formas como foram se concretizando, no espaço público, os interesses dos diferentes grupos sociais.

I. O referido trabalho concentra-se no levantamento dos estudos sobre a organização e gestão do sistema educacional e da instituição escolar, dimensões privilegiadas na reforma. Para a realização do estado da arte foram analisadas 186 produções, distribuídas entre os países da seguinte forma: Argentina (45); Brasil (62); Chile (36); México (43). 


\section{HOMOGENEIDADE E HETEROGENEIDADE NA REFORMA EDUCACIONAL}

A implementação das reformas educacionais na América Latina desencadeou a produção de um conhecimento crítico relevante que se dedica à compreensão da situação atual da educação na região. Essas análises mostram que se reconfigurou, nos anos 90, mediante a política de descentralização, a relação entre o Estado e a sociedade, tendo-se substituído seu papel de provedor direto de bens e serviços e de controle centralizado do conjunto das atividades sociais por funções de coordenação e regulação legal, dentre as quais a educação adquire relevância.

Ao reunirmos os dados dessas pesquisas, é possível observar que, na sua maioria, salientam como a descentralização teve em comum, nos diferentes países, um objetivo financeiro vinculado à crise fiscal dos governos nacionais, que se expressa em um novo cenário de distribuição de responsabilidades e de dinâmicas de negociação (González, Arango, 1997; Kisilevsky, s.d; Rivas, 2004; Riquelme, 2004; Calvo Pontón, 1997; Pardo, 1999; Donoso Díaz, 2004; García-Huidoro, 1999, 2004; García-Huidoro, Cox, 1999; Gluz, 2001 ; Davies, 1999; Bassi, 1996; Oliveira, 2004; Guimarães, 2004).

As pesquisas evidenciam a descentralização das funções administrativas para as instâncias locais e para as unidades escolares, centrada na transferência de competências, paralelamente a um processo de centralização do poder de decisão e do controle nos governos nacionais. Essa centralização é identificada nas pesquisas pela concentração das instâncias legais e de avaliação de sistema nos governos centrais.

No âmbito escolar, essa lógica da regulação consolidou uma nova relação entre o Estado e a sociedade que consubstanciou a mudança do teor da participação pela corresponsabilização dos indivíduos quanto ao provimento e qualidade da educação. O compartilhamento de deveres foi incentivado pelos governos nacionais com a definição de mecanismos que objetivavam a participação dos diferentes segmentos sociais no plano local e, principalmente, no gerenciamento das unidades escolares. Isso porque, para possibilitar o repasse dos recursos para as escolas de forma diferenciada e atrelada às demandas da comunidade escolar, os governos solicitam uma proposta pedagógica elaborada coletivamente que, além das necessidades, explicitem também as me- 
tas e estratégias de ação. Na análise da elaboração do projeto escolar, observa-se que a política oficial valoriza a particular capacidade de administrar os problemas e captar os recursos necessários, além de mobilizar a comunidade para ajudar as escolas a resolvê-los, como expressão da autonomia escolar.

Segundo as pesquisas, a incorporação do modelo gerencial e a adoção de novas estratégias de investimentos na educação revelam a implementação da lógica de mercado, perceptível também nos valores e práticas identificados nas instituições escolares (Birgin, Dussel, Tiramonti, 1998; González, 1999; Figueroa, 1997; Viriato, 200 I).

discurso participativo enfatizado no modelo gerencial produziu dois fenômenos que afetaram a dinâmica escolar. Por um lado, ocorreu a burocratização do cotidiano escolar e a formalização da participação das instâncias colegiadas, aumentando a atividade administrativa, as demandas das famílias e provocando uma mudança do perfil do trabalho escolar. Concomitantemente se fortaleceu a figura do diretor como gestor, distanciando-o das atividades pedagógicas, observando-se o esvaziamento da produção coletiva dos docentes, agravada pela instabilidade no emprego.

Por outro lado, o aumento das responsabilidades das instituições escolares e das famílias na gestão financeira da instituição e nas estratégias de resolução dos problemas educativos levou a um ativismo institucional e a uma relação de competitividade entre as escolas, dada a necessidade de elaboração constante de projetos, de contatos e parcerias com a comunidade para concorrer a novos recursos governamentais e privados (Birgin, 2000; Carnoy, 1998; Oliveira, Duarte, 1999; Teixeira, 1998; Fonseca, 2003).

Ao analisar esse processo, as pesquisas indicam que o espaço de autonomia construído a partir dessas políticas fica restrito às responsabilidades transferidas às unidades escolares em decorrência do processo de descentralização, mas não se configura como transferência efetiva de poder. A nova dinâmica estabelecida coloca as instituições com menos recursos - materiais, humanos e institucionais - em piores condições para elaborar projetos de qualidade, produzindo a atomização das instituições e fortalecendo a reprodução das desigualdades sociais (Tiramonti, 2004; Arroyo, 2004, Poliak, 2004; Mizala, Romaguera, 2000; Villegas, 1999; Fonseca 2003).

Esse processo comum de descentralização da educação efetuou-se de maneira distinta em decorrência da história de cada país da região, principal- 
mente no que diz respeito à lógica de configuração dos sistemas educacionais nacionais e das conjunturas nacionais nas quais se engendra a reforma educacional regional. São conjunturas que expressam tanto os processos de ruptura e continuidade emergentes do período anterior quanto os novos embates sociais, políticos e econômicos nacionais e internacionais.

$\mathrm{Na}$ Argentina, o novo papel do Estado que daria suporte à descentralização foi mediado, ao longo do período, pela forte crise econômica que se abateu sobre o país na década de 90 . Segundo as pesquisas, na reforma educacional argentina foi abandonado o caráter universalista do papel do Estado no provimento da educação pública, ganhando relevância o caráter compensatório das políticas nacionais (Duschatzky, Redondo, 2000).

Desde a constituição do sistema educacional, no século XIX, a democratização do ensino foi associada nesse país ao caráter universalista do Estado, visando à universalização do ensino primário para atender ao interesse nacional de homogeneização cultural e aos interesses dos setores emergentes (constituídos, sobretudo, por imigrantes) em relação à promoção e à participação política (Weinberg, 1987; Tedesco, 1982; Puiggrós, 1990).

Essa mudança na função social do Estado nacional aparece com bastante força nas pesquisas que analisam o Plano Social da Educação - PSE -, por ter sido a política mais importante do governo, destacando-se as conseqüências de sua natureza assistencialista na mudança dos comportamentos institucionais. O PSE foi a única política nacional ${ }^{2}$ dirigida diretamente às escolas de todo o país que tinham os maiores índices de população pobre na década de 90. As inquirições dos estudiosos clarificam como o plano foi inicialmente gestado para o atendimento de um tipo de população cujas condições de pobreza estavam vinculadas às características estruturais da sociedade, mas esse universo foi significativamente ampliado pela necessidade da inclusão de um contingente cada vez maior da população afetada pela crise econômica. $\bigcirc$ empobrecimento geral da população também afetaria as políticas de distribuição das competências educacionais, que aumentaram as responsabilidades das unidades escolares e das famílias. As pesquisas constatam, nos últimos anos da

2. Os investimentos para a implantação do PSE, ainda que realizados com recursos próprios do governo nacional, cumpriram a função de contrapartida aos empréstimos dos organismos internacionais para outros programas. 
década de 90, o crescimento da demanda familiar sobre a escola e o Estado para a resolução de problemas, sendo estes não só vinculados às questões materiais, mas também a comportamentos sociais, tais como a violência (Kessler, 2002; Tiramonti, 2004).

O estudos concluem que as práticas que consolidam o PSE nas escolas acabam produzindo comportamentos discriminatórios da pobreza, no lugar da função integradora que sustentava a lógica universalista anteriormente vigente (Birgin, Dussel, Tiramonti, 1998; Tiramonti, 200I).

É bastante consensual que o fortalecimento da compensação e do orçamento público seletivo no comportamento regulador do governo nacional, em termos de educação pública, fazia parte de um conjunto de estratégias vinculadas, de um lado, à diminuição dos gastos públicos e, de outro, à necessidade de gerar estratégias de contenção social - dado que a população, afetada pelo ajuste estrutural, manifestava seu descontentamento e exigia do governo nacional premência na resolução de problemas decorrentes de sua rápida depauperação (Barreyro, 200l).

Se uma das preocupações que orientam a análise das pesquisas na Argentina sobre as mudanças no papel do Estado é o abandono de seu caráter universalista, no caso do Brasil ocupa esse lugar a ausência de descentralização do poder na nova configuração que o Estado assumiu. Segundo as pesquisas, criou-se no país uma lógica de recentralização do poder no governo central, mediante um conjunto de normatizações (como o sistema de avaliação nacional e o Fundo de Manutenção e Desenvolvimento do Ensino Fundamental e de Valorização do Magistério - Fundef) que passou a regular a implantação da municipalização.

A descentralização proposta pelo governo central adquiriu um significado específico no caso brasileiro, porque acabou normatizando nacionalmente uma diversidade de redes que configuravam o ensino público desde seu início, no século $X X$, quando os estados e municípios assumiram a responsabilidade pelo ensino fundamental. Tal diversidade se manteve no período centralizador da ditadura da segunda metade do século $X X$ e foi acentuada durante a democratização, após a década de 80 , com a redefinição das relações entre as três instâncias federativas (União, estados e municípios). A estes dois últimos foi reafirmada a atribuição de assumirem a pré-escola, o ensino fundamental e o ensino médio. 
A política educacional mais polemizada pelos pesquisadores foi a municipalização do ensino fundamental. Isso devido às alterações provocadas pela redistribuição de competências e atribuições entre as distintas esferas do poder público nas diferentes redes de ensino e às expectativas de autonomia que se foram construindo socialmente em contraposição ao período ditatorial (Bezerra, 1997; Costa et al., 1997).

No México, configurou-se um novo federalismo que rompeu com a idéia do Estado nacional como único responsável pela educação pública. Criara-se, já no século XIX, um sistema de educação nacional centralizado, que visou a uma homogeneização educacional e cultural da população para a consolidação da nação e de uma sociedade democrática, liderada, no esforço pós-revolução, pelo Partido Revolucionário Institucional - PRI -, advindo daí sua forte conotação laica e republicana.

A constituição do novo federalismo foi expressão de uma crise de hegemonia em todos os âmbitos da nação, de que resultou um consenso nacional sobre a necessidade da descentralização, o que permitiria a recomposição dos atores sociais na disputa pelo poder. Assim como no Brasil, embora por razões distintas, a preocupação dos pesquisadores é identificar a descentralização do poder. As análises constatam que, coerentemente com a tendência regional, manteve-se a forte centralização do governo nacional, por meio de funções normativas e avaliativas. Ao mesmo tempo, evidenciam a manutenção da hegemonia do Sindicato Nacional de Trabajadores de la Educación - SNTE - no interior do poder central e sua liderança na gestão educacional do país (Street, 2001 ; Calvo Pontón et al., 2002).

Um espaço ainda privilegiado pelo governo nacional na época da pesquisa era a responsabilidade pela implementação de programas compensatórios voltados a grupos de extrema pobreza, mantendo a tradição de garantir que as escolas chegassem a qualquer lugar do país. A produção acadêmica centrou sua atenção na avaliação dos resultados desses programas em sua nova dimensão social, ou seja, na melhoria da qualidade da rede de ensino.

Os diferentes diagnósticos indicam que não está havendo diminuição da desigualdade educacional, ainda que reconheçam aspectos positivos no tocante às finalidades dos programas. Embora não tenham percebido mudanças no rendimento nem na adequação dos programas e práticas pedagógicas quanto à organização multisseriada das escolas, reconhecem que os incentivos aos 
docentes têm estimulado sua fixação nas regiões rurais de extrema pobreza e incentivado o acesso das crianças ao material didático.

É bastante presente nos estudos no México a preocupação com o comportamento institucional da educação diante das desigualdade sociais, tendo como referência o princípio de eqüidade educacional. O resultado das pesquisas aponta que, a despeito da quase universalização da escolaridade, ainda há problemas sérios de repetência e evasão e que a qualidade de ensino está distribuída de forma desigual entre as regiões e classes sociais (Quirós, 2000; Bracho, 1997). Uma das questões destacadas por alguns pesquisadores é que a segmentação no interior da escola pública não resulta da implementação de estratégias homogeneizadoras em situações heterogêneas. A situação é muito mais grave: o que sucede é que o sistema educacional, no seu funcionamento cotidiano, está proporcionando - tanto em termos quantitativos quanto qualitativos - insumos diferenciados aos distintos contextos sociais, reproduzindo e consolidando a diferenciação (Schmelkes, 1995).

Já no Chile, que seguiu caminho dessemelhante em relação aos outros países, a década de 90 não assistiu nem a uma reestruturação do Estado (como no México) nem a uma disputa pela hegemonia de diferentes projetos de Estado (a exemplo do Brasil e da Argentina) que afetasse a política educacional. Pelo contrário, já havia lá um Estado mínimo consolidado que se ancorava na lógica de regulação do mercado e que ainda não incorporava devidamente o setor educacional (Núñez, 1994, 1999, 1999a, 199b). Segundo os pesquisadores, na década de 90 o Estado nacional reconfigurou o sistema de subvenções e desregulou o setor (Vargas, Vargas, 1997), à semelhança da lógica vigente nas outras áreas sociais, assumindo o governo nacional a responsabilidade de dirimir da falta de eqüidade vigente na educação.

A desregulação do setor educacional afetou o trabalho da escola e, particularmente, a condição dos professores, de forma mais contundente do que nos outros países, devido às estratégias adotadas pelo governo chileno (Pereira, 2000; Serrano, Fernández, 2001 ; Díaz, 2002; Espinoza, 1997). No Chile, o trabalho docente sofreu um processo de desregulação eqüivalente ao vivenciado pelas outras categorias de assalariados em décadas anteriores. As pesquisas registram a flexibilização contratual e salarial (Carnoy, I 998, Díaz, 2002), o esvaziamento das negociações coletivas, a perda da estabilidade e a desvinculação das contratações com o estatuto do magistério (Lavia, 2002). Ainda que 
a desregulação do trabalho tenha afetado o conjunto dos profissionais da área, nas escolas com maior subvenção não se configurou a deterioração do trabaIho escolar (Mizala, Romaguera, 2000; Pereira, 2000). Ao mesmo tempo, a lógica de subvenção, juntamente com a desregulação do trabalho, acirra a competição entre os profissionais da área de forma mais contundente que a observada nos demais países.

Não há consenso entre os pesquisadores nem na sociedade sobre as conseqüências da desregulação, uma vez que as análises são perpassadas pela marca do antagonismo ideológico (Illanes, Lagos, 1998, Tiznado, 2000; Escoffier, 1995; Narciso, 1997; Mizala, Romaguera, 1998). Além disso, as pesquisas mostram que a idéia de que a eqüidade no sistema educacional poderia ser garantida pelo investimento público que regulasse as diferenciações sociais e institucionais não se concretizou (Figueroa, 1997; Bravo, 1999) ainda que o governo chileno tenha realizado um forte investimento em políticas de discriminação positiva, estendidas gradativamente para toda a rede (Yepes, 2000; Prado, Gajardo, 1995; San Miguel, 1999).

O processo de descentralização em cada um dos países, ao configurar um novo papel do Estado nacional, alterou as relações de poder entre o governo central e os locais, o que, por sua vez, irá constituir-se em dimensão fundamental na instituição da nova organicidade dos sistemas educacionais.

No caso da Argentina, as alterações na estrutura do sistema e a finalização da transferência do serviço educacional para as instâncias regionais iniciado pelos governos ditatoriais, a que se somou a preexistência de um federalismo centralizado, conformam a nova organicidade do sistema educacional.

No início da década de 90, a transferência das escolas de ensino secundário, do infantil e do superior, até então sob responsabilidade do Ministério de Cultura e Educação, consolidou a descentralização da responsabilidade quanto ao provimento e da quase totalidade do financiamento do sistema educacional para as províncias ${ }^{3}$. A partilha de responsabilidades e compromissos de financiamento para a implementação da reforma educacional entre a nação e as províncias foi objeto do Pacto Federal Educativo - PFE. No entanto, a

3. Durante o governo militar (de 1976 a 1982), foram transferidas às províncias todas as escolas de ensino fundamental e a maior parte das do ensino secundário. 
política educacional tornou-se, durante todo o período, um espaço de negociação e de tensões com as províncias.

Observa-se, ainda, a transposição da lógica da centralização às províncias, permeada pela manutenção da forte dependência de algumas delas em relação ao governo central. Essa vinculação decorreu não só da centralização tributária, mas também, em um primeiro momento, da centralização do poder na definição de prioridades de investimento do grande montante de recursos oriundos dos organismos internacionais para a reforma educacional (Rivas, 2004).

Os estudos acrescentam que, enquanto o governo nacional dispunha desses recursos (o que lhe permitiu, entre outras coisas, compor um corpo técnico competente para fundamentar a reforma), foi mínima a possibilidade de debate e negociação da maioria das províncias. Essa situação se deteriorou diante da forte crise financeira que assolou o país, fragilizando o poder central, que se viu impossibilitado de continuar implantando políticas, bem como com a dificuldade dos governos provinciais de sustentarem propostas alternativas (Vior, 1999; Tiramonti, 200I).

O caráter centralista e camuflado que caracterizou todo o processo de negociações com as províncias manifesta-se também na dinâmica da gestão educacional provincial (Tedesco, Tenti Fanfani, 200 I). Em muitas delas, a gestão centralizada resultou no desmantelamento das instâncias colegiadas, diferentemente dos outros países, nos quais foi proposta uma organização administrativa que contemplasse a coletivização das decisões (Vior, 1999; Rivas, 2004).

As mudanças na estrutura do sistema educacional significaram a substituição da organização tradicional do ensino (primário, de sete anos, e secundário, de cinco) por um ciclo de educação inicial de dois anos (quatro e cinco anos de idade), outro de educação geral básica - EGB -, de nove anos, e o nível polimodal, de três anos, tendo sido a obrigatoriedade estendida de sete para dez anos. Essa mudança, que se pressupunha radical e de complexa implementação, esvaziou-se, consolidando a heterogeneidade do serviço educacional no país (Tedesco, Tenti Fanfani, 200I).

Alguns pesquisadores ponderam que a nova estrutura do sistema que se pretendeu implementar não era essencial para resolver os problemas educacionais e, ao mesmo tempo, demandava um montante de recursos e de ações inexistentes naquele momento. 
As pesquisas resgistram que, quando implantada a EGB3 em continuidade ao antigo ensino primário, houve um aumento da permanência dos adolescentes na escola (Duschatzky, 1999; Kricheskye, Cappellarcci, 1999). No entanto, a implementação da nova estrutura não foi acompanhada pela correspondente formação docente nem pela adequação dos espaços institucionais e condições administrativas necessários para enfrentar as novas demandas (Romagnoli et al., 2002; Oyola, 1998).

A heterogeneidade das situações provinciais consolidada no marco da crise de hegemonia do Estado nacional resulta, segundo as pesquisas, em uma organicidade que tem como principal característica a fragmentação e a reprodução da desigualdade (González, Arango, 1997; Tiramonti, 200 I; Rivas, 2004).

Nas análises sobre a gestão escolar, as pesquisas indicam que a incorporação de uma lógica mercadológica de transferência de responsabilidades (antes afetas ao Estado) para as escolas e as famílias aprofunda a fragmentação em face da diversidade de culturas institucionais e das características socioeconômicas e culturais da comunidade.

No México, a organicidade do sistema educacional inerente ao novo federalismo evidenciou a recente dinâmica que alterou a relação entre o governo central e os regionais e terminou por legitimar diferentes atores políticos, ao mesmo tempo em que se recompuseram as forças tradicionais. Nesse contexto, a política de descentralização desencadeada pela reforma educacional, que se pretendia inovadora, ficou subordinada à lógica da política partidária, na qual o corporativismo do SNTE se manteve predominante (Loera, Sandoval, 1999; Calvo Pontón et al., 2002; Loyo, Muñoz, 2001; Ornelas, 2002).

A dinâmica de negociação entre o governo central e os governos estaduais foi acirrada pela falta de uma política fiscal que possibilitasse dar visibilidade aos critérios utilizados para as transferências de recursos econômicos à educação. $\bigcirc$ controle centralizado desses recursos levou, segundo os especialistas, a uma fragmentação das negociações tendo em vista o financiamento educacional, o que resultou no fortalecimento do governo central e daqueles estados com maior possibilidade de barganha (técnica ou política). Decorre daí que, segundo as pesquisas, as transferências federais dos recursos aos estados não tenham visado, de fato, à redução das desigualdades regionais (Hernández, 1999; Latapí, Herrero, 2000). 
Tanto no México quanto na Argentina, é possível observar que as condições históricas de suas dinâmicas federalistas se manifestaram na dificuldade de institucionalizar uma nova normatização redistributiva, submetida a uma negociação política constante.

No México, além da análise da dinâmica distributiva da descentralização e suas conseqüências, um vasto conjunto de pesquisas enfoca a importância da descentralização como eixo principal da viabilização de inovações, acompanhando os pressupostos da reforma na América Latina. Segundo vários autores, a descentralização abriu espaço para que germinassem condições políticas, técnicas e financeiras de inovação em distintos planos da organização e estrutura das redes educacionais locais (Pardo, 1999; Camacho, s.d.).

Os estudos sobre as políticas educacionais locais permitem constatar a diversidade de situações no país - tanto no que tange ao caráter ideológico das propostas quanto à diferenciação das possibilidades concretas de sua implantação, tal como se verificou em outros países (Espinoza, 1999; Carmona, 1996).

Um dos temas comuns encontrados nas pesquisas sobre as realidades locais é o papel da supervisão nas dinâmicas dos sistemas estaduais e das unidades escolares. A supervisão despontou na década de 90 como um dos tópicos destacados nos debates sobre a gestão da educação. Essa preocupação demonstrava o interesse de efetivar mudanças no perfil da categoria, de maneira que esta promovesse a implantação da reforma nas escolas. Reconhecese, assim, que a supervisão ocupava uma posição estratégica na estrutura do sistema educacional mexicano, tanto na articulação entre a administração central - seja nacional ou estadual - e as unidades escolares quanto nas dinâmicas institucionais das escolas. $O$ entrosamento do SNTE com a Secretaria de Educação Pública e as instituições escolares, principalmente por meio da supervisão escolar, produziu uma lógica de controle bastante complexa do sindicato sobre a vida cotidiana nas escolas e sobre os docentes.

As pesquisas observam que a supervisão, apesar da força institucional que possuía, volta suas ações para as atividades-meio, perdendo a perspectiva das finalidades de sua função propriamente pedagógica. $\bigcirc$ burocratismo em que se vêem envolvidos os profissionais da educação é útil para a manutenção do controle da escola pelo sindicato e para a mediação entre escola e administração central (Ezpeleta, 1997; Pardo, 1999; Calvo Pontón et al., 2002). As pesquisas indicam ainda que o discurso da necessidade de reposicionar a função 
pedagógica do supervisor, preconizado pelas secretarias de educação nacional e estaduais, não se materializou na relação que elas estabeleceram com a supervisão, o que reforçou o caráter burocrático da função do supervisor.

As investigações que abordam a dinâmica escolar atestam, também, o isolamento e o individualismo da atividade docente, dadas as suas condições de trabalho e a dinâmica burocratizada da escola (Sandoval, 2002; Ezpeleta, 2003). Uma das políticas que mais têm afetado essa dinâmica é, segundo os pesquisadores, o Programa da Escola de Qualidade - PEC. Segundo a bibliografia, o PEC reflete alguns dos traços mais importantes do acordo empresários-governo, partindo do pressuposto de que o processo da melhoria de uma escola pode deslanchar quando se oferece à sua direção e ao corpo docente a possibilidade de receber recursos extras para implementar um projeto escolar próprio. Ao voltar sua finalidade à competição por financiamentos para a escola, alterou-se a dinâmica implementada anteriormente pelo Programa de Gestão da Escola Primária - PGEP -, que priorizava a reflexão da gestão pedagógica para a melhoria da qualidade de ensino (López, 2003; Bonilla, 2002; Aboites, s.d.; Ezpeleta, 2003).

As pesquisas constatam o delineamento de nova dinâmica institucional a partir do PEC, comum aos demais países analisados, de incremento do burocratismo em detrimento do aspecto pedagógico. Também registram que o desempenho das instituições depende da capacidade da equipe docente de elaborar projetos e captar recursos, reproduzindo-se, assim, a desigualdade no interior do sistema educacional (Bonilla, 2002; García, Romero, 2003).

A nova lógica para a gestão escolar implantada pelo PEC vinculou a possibilidade de participação das escolas no programa à constituição de conselhos escolares e à participação dos diferentes segmentos na elaboração dos projetos escolares. As pesquisas evidenciam dissociação entre o discurso das autoridades escolares e a prática participativa dos pais, além de heterogeneidade nas formas de funcionamento dos conselhos e no envolvimento dos pais na escola (Loera, 2003; García, Romero, 2003).

As práticas participativas da comunidade na instituição escolar têm origem na revolução mexicana, com a mobilização ocorrida em prol da universalização do ensino primário. Essas práticas tenderam, principalmente, para o envolvimento dos pais na manutenção das escolas e na implementação dos programas compensatórios (Rockwell, 1997). As pesquisas demonstram que 
muitas dessas práticas permanecem, porém adquiriram novo sentido. A percepção de que os pais de menor poder aquisitivo são os que mais contribuem (em decorrência da omissão do Estado nas escolas mais carentes) leva os autores a ponderarem sobre a falta de eqüidade e a não-gratuidade da escola pública (Mercado, 1997). Observa-se, também, que a participação dos pais nas políticas compensatórias tende a "compensar" a ausência do Estado no provimento das condições necessárias para o funcionamento das escolas e no controle da implantação dos programas (Ezpeleta, Weiss, 2000).

Podemos extrair das análises dos autores abordagens distintas no estudo da relação entre a comunidade e a unidade escolar. Uma delas explicita as conseqüências do esvaziamento do caráter mobilizador da participação das famílias, advindo da tradição constituída no período revolucionário e suas conseqüências para a gratuidade e eqüidade do ensino. Inicialmente, a comunidade integrava de forma espontânea o esforço da nação no provimento de educação, independentemente da institucionalização ou legalização dessa relação, mas, progressivamente, as escolas mais pobres passaram a depender da contribuição das famílias de seus alunos.

Uma outra abordagem identificada é a que se expressa no estudo da relação entre a participação e a sua institucionalização, sendo que esta materializa a proposta de "democratização do poder" via burocracia participativa.

Por fim, a terceira, analisa a reconfiguração da participação social e constata que, inicialmente voltada para a democratização das relações da escola, agora visa à liberalização das instituições, para buscarem formas e condições de se autogerirem e sustentarem.

No Brasil, as alterações da relação entre o governo nacional, os estados e os governos locais, assim como a nova organicidade do sistema educacional, estão normatizadas no Fundef, que se constitui no principal mecanismo de regulação da municipalização. Esse fundo foi implementado para redistribuir os recursos financeiros em todo o país, objetivando a universalização do ensino fundamental.

A política de expansão do ensino, embora seja comum entre os diferentes países da região, adquire conotações distintas segundo o grau de desenvolvimento da educação formal em cada um deles. Enquanto no Brasil foi necessário, primeiramente, concentrar-se na universalização do ensino fundamental devido à escassa cobertura historicamente configurada -, no México e na Ar- 
gentina as políticas para o ensino básico puderam focalizar, desde o início, a expansão do nível médio. No Chile, por sua vez, chegou-se a propor, além disso, a obrigatoriedade da educação infantil.

Passados alguns anos da implantação do Fundef no Brasil, o conjunto das pesquisas acusa a consolidação de uma nova organicidade do sistema educacional, que contém uma significativa diversidade de situações no país (Viriato, 2001 ; Martins, 2004; Bassi, 2001; Barretto, 1995; Fonseca, 1995; Gomes, 1995; Oliveira, Duarte, 1997).

As disparidades regionais já se vinham acentuando, como resultado das iniciativas estaduais e municipais, e se reforçam ainda mais com a lógica de redistribuição de responsabilidades entre os diferentes órgãos de governo e a instituição escolar, advinda da reforma.

Verificou-se que o desempenho, o acesso às informações, a capacidade de atendimento e de institucionalização, bem como a disponibilidade de recursos dos órgãos de controle e gestão, são distintos e desiguais nas redes de ensino existentes no país (Davies, 1999). Essa desigualdade foi reforçada pela diminuição de investimentos federais, produzida, entre outras razões, pela transferência de responsabilidades financeiras às instâncias federadas que possuíam condições muito díspares de investimentos e pelo não cumprimento, pelo governo federal, do valor do custo/aluno estipulado por lei. Em contrapartida, a implementação do Fundef resultou, nos estados e municípios com menores recursos, no aumento dos salários dos professores, enquanto os municípios que já vinham investindo numa política salarial de valorização da categoria foram prejudicados com o congelamento e a conseqüente redução dos salários docentes (Fracalanza, 1999).

A concentração de uma porcentagem importante dos recursos financeiros no desenvolvimento do ensino fundamental estipulada pelo Fundef trouxe, segundo as pesquisas, resultados antagônicos na cobertura do sistema educacional. Obteve-se a quase universalização do ensino fundamental em todo o país, com o crescimento das redes municipais de ensino. Esse crescimento ocorreu principalmente pela transferência das matrículas estaduais, em detrimento do atendimento à educação infantil e de jovens e adultos, que já estava sob responsabilidade dos municípios (Gonçalves, 1998).

Paralelamente, essa dinâmica se justapôs às políticas de gestão local que, em decorrência do contexto histórico de seus projetos políticos, continuaram 
mantendo uma autonomia relativa diante das mudanças da regulação da organicidade do sistema (Bof, 1999).

As pesquisas que analisam os projetos políticos locais nas suas modalidades de gestão identificam duas concepções dominantes no país que poderíamos chamar como: a "democrática" e a "gerencialista" (Fonseca, 2003; Jacobi, 2000; Torres, Garske, 2000).

Nos municípios que levaram à conclusão de um projeto de gestão democrática, observou-se que ele teve como eixo principal a autonomia da escola, que seria possibilitada pela transferência de poder das instâncias centrais para as unidades escolares e pela inclusão da comunidade educacional nos espaços de decisão. Tais intencionalidades se expressaram pela constituição de mecanismos e práticas de decisão coletiva que, segundo constatam os pesquisadores, nem sempre se efetivaram, em vista da descontinuidade dessas medidas. Isso ocorreu e ainda ocorre devido à dificuldade das autoridades locais de lidar com os conflitos e criar uma cultura participativa que sustente práticas colegiadas de gestão, integrando os diferentes segmentos à dinâmica escolar de forma mais permanente (Castro, 2000; Cardoso, 1995; Mattos, 1998; Oliveira, 2000; Pithan, 1995; Souza, 2001; Neves, 1999). Os pesquisadores observam ainda que o discurso da descentralização se limitou à desconcentração de funções e à ausência de condições e orientações que efetivassem a democratização ou que provocassem, de fato, uma alteração substantiva nas escolas quanto a seu desempenho (Mendonça, 2000; Pavan, 1998; Schmidt, 2000; Viriato, 200 I) .

As pesquisas que, por sua vez, analisam criticamente a lógica gerencialista vigente nas dinâmicas escolares afirmam que as escolas e as famílias são incentivadas a assumir novas responsabilidades, sob o argumento da autonomia escolar, embora sem os correspondentes insumos materiais, financeiros, institucionais e de formação (Fiorini Filho, 1996). Esse pressuposto está ancorado, segundo os estudiosos, em um discurso participativo que oculta processos de privatização do serviço público, averiguados nas análises da dinâmica escolar que se estabelece quando as escolas concretizam parcerias com instituições privadas para colaborar com sua gestão. Nos estudos, observa-se que a motivação das empresas está voltada para a melhoria de sua imagem social e que os recursos alocados são essencialmente assistencialistas (Melo, 200 I; Sousa, 2000; Vaini, 1999). Os pesquisadores concluem, ainda, que as escolas 
obtêm benefícios, principalmente financeiros (ainda que momentâneos), e que essas parcerias geralmente são frágeis, dada a sua informalidade.

As mudanças institucionais ocorridas na gestão escolar produziram, entre outras coisas, a burocratização da participação e o aumento das atividades administrativas (Fernandes, 1997; Paro, 1996), à semelhança do que ocorreu nos outros países da região. Mas no Brasil essas mudanças institucionais imbricaram-se, em alguns estados e municípios, com práticas (vigentes desde a década de 80) que ampliavam a participação da comunidade escolar. Entre essas, destaca-se o provimento do cargo de diretor pelo voto direto da comunidade escolar.

Nos estados em que prevalecia o clientelismo e o patrimonialismo, a implantação da eleição para diretor foi reconhecida como um avanço no esforço de superação desse comportamento histórico, embora, em alguns casos, tais condutas tenham continuado a se reproduzir, por meio de comportamentos populistas e corporativistas (Paro, 1996). Também se tornou manifesto que o aumento da legitimidade dos diretores eleitos e o maior incentivo à participação da comunidade não resultaram na melhoria da qualidade (Cruz, Maia, Vieira, 1999; Silva, 200 I; Teixeira, 1998; Cabral Neto, Almeida, 2000) nem em inovações na gestão escolar, conforme as expectativas que justificaram a implantação dessas práticas.

A descentralização da administração pública da educação no Chile deuse, de forma diferente da dos outros países, no interior da lógica unitária do poder político vigente no país. Caracterizou-se pela criação de instâncias administrativas municipais e pela normatização da participação do setor privado na gestão pública, permitindo a estes, inclusive, que assumissem a gestão das unidades escolares públicas. A descentralização no Chile decorreu não apenas da influência dos organismos internacionais que aportaram recursos para a reforma, mas também de outros fatores específicos da realidade chilena, entre os quais se salientam a vontade da população de voltar a participar, o que havia sido interrompido pela ditadura, e o endividamento do Estado, agravado por uma burocracia custosa, daí a ênfase em partilhar com a sociedade civil os investimentos na educação (Tapia, 1999).

Nesse país a política de municipalização contemplou a transferência de responsabilidades e competências do governo central para os municípios e a criação de instâncias administrativas colegiadas de gestão municipal. Previa, 
ademais, a elaboração de um plano educacional pelo conjunto da rede local (Espinoza, 1997; Navarro, 2000). No entanto, as pesquisas mostram que a municipalização reduziu-se à transferência da administração de serviços educacionais para os municípios, excluindo-se as funções técnico-pedagógicas, que permaneceram nas mãos do ministério, das respectivas secretarias regionais e da direção provincial (Navarro, 2000; Villegas, 1999). Observam, ainda, que a consolidação de uma proposta coletiva para o município mostrou-se inviável, porque nem sempre esses priorizavam a educação no rol de políticas públicas ou possuíam a competência técnica necessária - e porque sua consolidação pressupunha uma rápida mobilização das escolas para a tomada de decisões e projeções futuras (Chile, 200I).

A normatização da participação do setor privado na gestão pública ocorreu principalmente na reconfiguração da lógica institucional da escola pública, pela regulamentação do sistema de subvenções. Configura-se, assim, um sistema composto por escolas municipais, subvencionadas, privadas e privadas subvencionadas (Mizala, Romaguera, Fareen, 1998; Gonzáles, 1999; Lavia, 2002).

Além das mudanças na lógica da gestão escolar, a incorporação da iniciativa privada na gestão pública da educação propiciaria uma correlação de forças favorável aos interesses da primeira na definição de um projeto nacional. Essa nova lógica não apenas muda as relações no interior das unidades escolares como também altera o caráter da participação da comunidade (Poblete, 1996; Reca, 2002).

Segundo estudos, a reconfiguração das relações do Estado com a sociedade transformaram a tradicional cultura de participação coletiva (Gubbins, 200 I), já fragilizada pelo governo militar, em uma cultura de participação privada, que defende seus direitos como consumidora (Carnoy, 1998; Reca, 2002). Essa nova organicidade foi assumida pelo governo central como a modernização da educação em prol da eqüidade e da qualidade (Belleï, 200 I). No entanto, como advertem alguns pesquisadores, tal propósito não se confirmou, pois as escolas desenvolveram comportamentos discriminatórios para garantir a obtenção da subvenção condicionada ao desempenho dos alunos (Bravo, 1999, Carnoy, 1998). Dessa forma, nas escolas subvencionadas, gerou-se um mecanismo de privilégios a estudantes com melhores condições culturais e econômicas. Como decorrência, as unidades com menores recursos, principalmente as municipais, passaram a acolher os estudantes com dificuldades de 
aprendizagem e, em geral, advindos de famílias em piores condições socioeconômicas e com menos possibilidades de investir na instituição. Reforça-se, assim, a discriminação e a desigualdade no interior do sistema educacional (Serrano, Fernández, 200 I; Figueroa, 1997).

A reprodução da desigualdade é observada pelos pesquisadores também quando analisam a implantação da Jornada Escolar Completa - JEC. Ponderam que sua validação exige uma nova organização interna dos estabelecimentos e uma infra-estrutura mínima para suportar toda a demanda (Herrera, 1996).

O processo requer, ainda, um novo tipo de trabalho docente e, por conseqüência, maior disponibilidade de tempo, já que o professor terá de adaptar seus planos de trabalho a cada realidade. Consoante com essa análise, a falta de recursos financeiros (para cobrir os gastos com infra-estrutura, alimentação, investimento em cursos de capacitação dos docentes) constitui um dos maiores problemas na consolidação da JEC, cujo sucesso depende do aumento da subvenção estatal às escolas.

Todas essas constatações não invalidam o consenso em torno da descentralização do sistema educacional. Contudo, no interior desta, os pesquisadores observam uma tensão social entre os defensores de maior e de menor regulamentação da autonomia das escolas subvencionadas em relação ao governo central.

É comum encontrar, nas alternativas propostas para enfrentar os problemas detectados por alguns autores, o questionamento das regulamentações realizadas nos últimos anos. Aponta-se que as deficiências do sistema decorrem de mecanismos de controle ainda centralizados nas mãos do governo nacional (Villegas, 1999). A esse respeito, há também raciocínios que admitem que quando o aumento de responsabilidades vem acompanhado de recursos públicos ou privados, parece haver maior estímulo às ações voltadas à liberalização das normas, de forma que tais recursos não sejam submetidos a nenhum controle. Em contrapartida, quando o aumento de responsabilidades não vem acompanhado do correspondente crescimento de recursos, solicita-se maior presença do Estado (Bravo, Marinovic, s.d; Yepes, 2000).

A assunção, pelo setor privado, de responsabilidades e atribuições na gestão da educação pública demonstra diferentes graus de consolidação, segundo a tradição de participação desse setor. A reordenação do sistema de subvenções no Chile - que, como vimos, institucionaliza a participação da ini- 
ciativa privada na gestão da educação pública - dá continuidade a uma política de abertura para o mercado na gestão do espaço público.

\section{CONCLUSÃO}

Ao longo deste texto, quando analisamos os aspectos comuns e as especificidades nas mudanças ocorridas na organicidade do sistema educacional na Argentina, no Brasil, no Chile e no México, deparamo-nos com uma diversidade no interior da homogeneização aludida no debate regional. As especificidades das realidades sociais apresentam-se nas pesquisas, principalmente por meio de suas categorias de análise que, ao mesmo tempo, se revelam no caráter do conhecimento produzido.

Além da relação entre a produção intelectual e a base social de onde emergem e com a qual interagem, encontramos também a vinculação historicamente configurada das tendências nacionais e internacionais consubstanciando impactos distintos da reforma nos países.

processo de indução externa da reforma desencadeada no início da década de 90 configurou-se de forma particular em cada país segundo os embates políticos nacionais pela construção de uma nova hegemonia, que se expressam em uma nova normatividade da política educacional na década seguinte. Esses embates tornaram públicas as expectativas e os diferentes interesses presentes nos cenários nacionais que mobilizaram as sociedades até o início da década de 90 quando, então, consubstanciado o predomínio de alguns setores, observou-se a centralização das decisões político-educacionais no âmbito governamental, restringindo-se suas negociações a alguns setores nacionais e internacionais.

A partir daí, conforme as reflexões apresentadas neste artigo, instaurouse na América Latina, ao longo dos anos 90, um novo modelo de organização e gestão do sistema e de suas instituições. Isso nos apresenta, no limiar do século XXI, um cenário educacional que, sob o fetiche da modernidade e da democratização, respondeu à necessidade de adequação da gestão da educação pública às mudanças da lógica de regulação instaurada pelo novo estágio do capitalismo. Esse cenário, revelado pelas pesquisas em cada um dos países, permite-nos levantar a hipótese de que o centro da reforma não foi a instituição escolar - tal como proclamado - mas a lógica e as instâncias de regulação 
social. Ao contrário, o foco da transformação foi o governo central, com as adequações que se fizeram necessárias nas demais instâncias de decisão governamental, inclusive na instituição escolar.

Observa-se o estranhamento ${ }^{4}$ da dinâmica institucional concretizada ao configurar-se contraditória em relação às finalidades da reforma educacional, legitimadas na lógica capitalista contemporânea, sob o fetiche da modernidade e da democratização. Nesse engendramento acentuam-se problemas que supostamente se pretendia eliminar como, por exemplo, o aumento da desigualdade, em face da intencionalidade explicitada de socialização eqüitativa do conhecimento. As diretrizes educacionais em cada país demonstraram diferentes graus de concretização, conforme as particularidades dos poderes executivos e suas alianças, a ruptura ou a continuidade diante de projetos políticos anteriores e a mobilização e resistência de diversos segmentos da sociedade, o que Ihes conferiu diferentes graus de legitimidade.

$\bigcirc$ que se observa é que a historicidade, característica da realidade educacional nesses países, tem sofrido, no México, o que poderíamos denominar uma "ruptura conservadora", pelo seu caráter regressivo; no Chile, uma "continuidade conservadora", dado o aprofundamento e a ampliação das propostas de cunho neoliberal; no Brasil, uma renovação conservadora, por seu ativismo inovador; e na Argentina, uma ruptura interrompida, em razão do estancamento das renovações pretendidas.

○ "novo conservadorismo" na realidade educacional expressa a finalidade comum apontada, enquanto a historicidade vigente em cada país se revela na especificidade de suas metas e de suas estratégias, dentre as quais se destacam a expansão do ensino, a desregulação do trabalho docente e a reconfiguração das responsabilidades no âmbito educacional.

\section{REFERÊNCIAS BIBLIOGRÁFICAS}

ABOITES, H. La Propuesta de educación básica del gobierno de Vicente Fox. un análisis desde el Programa de Escuelas de Calidad. Xochimilco, Ciudad de México: Universidad Autónoma Metropolitana, Departamento de Educación y Comunicación, s.d.

4. $\bigcirc$ estranhamento, conceito cunhado por Marx, é inerente à alienação e se manifesta no interior do processo de produção capitalista no qual o objeto produzido afronta o produtor como ser estranho, como um poder independente dele. 
ARROYO, M. ¿Hay en la escuela algo que tenga que ver con un proyecto común? Reflexiones sobre las relaciones entre las políticas, la solidaridad y la escuela. In: TIRAMONTI, G. La Trama de la desigualdad educativa: mutaciones recientes en la escuela media. Buenos Aires: Manantial, 2004. p.|44-|46.

BARRETTO, E. S. de S. Descentralizar e redistribuir nos sistemas de ensino. Cadernos de Pesquisa, São Paulo, n.95, p.73-78, nov. 1995.

BARREYRO, G. B. Políticas educativas en la Argentina a fines de/ siglo XX: un estudio del Plan Social Educativo. Buenos Aires, 200 I . Disert. (maest.) Faculdad Latinoamericana de Ciencias Sociales.

BASSI, M. Gestão e financiamento da educação básica: repercussões do Fundef em sete municípios paulistas. São Paulo, 200 I. Tese (dout.) Pontifícia Universidade Católica de São Paulo.

Política educacional e descentralização: uma crítica a partir da análise da descentralização financeira dos recursos públicos enviados às escolas no Estado de Minas Gerais. São Paulo, 1996. Dissert. (mestr.) Faculdade de Educação da Pontifícia Universidade Católica de São Paulo.

BELLEİ, C. ¿Ha tenido impacto la reforma educativa chilena? Revista Educación, n.29l , p.2940, dic. 2001 .

BEZERRA, A. A. C. Gestão democrática da construção de uma proposta curricular no ensino público: a experiência de Aracaju. São Paulo, 1997. Tese (dout.) Faculdade de Educação, Universidade de São Paulo.

BIRGIN, A. Novas regulações do trabalho docente: o caso da Argentina. Cadernos de Pesquisa, São Paulo, n. I I I, p.95-1 13, dez. 2000.

BIRGIN, A.; DUSSEL, I.; TIRAMONTI, G. Nuevas tecnologías de intervención en las escuelas: programas y proyectos. Propuesta Educativa, Buenos Aires: Flacso, n. I 8, jun. 1998

BOF, A. M. Mudando a gestão da escola para melhorar a qualidade: o caso de Rondonópolis. Ensaio. Rio de Janeiro, v.7, n. 25, p.4I5-443, out./dez. 1999.

BONILLA, R. Programa de transformación de la gestión escolar. Ciudad de México: Subsecretaría de Educación Básica y Normal, Direción General de Investigación Educativa, 2002. (Documento de trabajo)

BRACHO, T. Educación básica en México (1990-1996). Ciudad de México: Cide, División de Administración Pública, 1997.

BRAVO, D. Rendimiento educacional, desigualdad y brecha de desempeño privado y publico: Chile 1982-1997. Santiago, 1999. Thesis (doct.) Faculdad de Ciencias Económicas y Administrativas, Universidad de Chile. 
BRAVO, D.; CONTRERAS, D.; SANHUEZA, C. Rendimiento educacional, desigualdad y brecha de desempeño privado y publico: Chile 1982- 1997. Santiago: Faculdad de Ciencias Económicas y Administrativas, Universidad de Chile, ago. 1999. (Documento de trabajo, 163)

BRAVO, D.; MARINOVIC, A. La Educación en Chile: una mirada desde la economia. Santiago: Universidad de Chile, Faculdade de Ciencias Económicas y Administrativas, s.d.

CABRAL NETO, A.; ALMEIDA, M. D. Educação e gestão descentralizada: conselho diretor, caixa escolar, projeto político-pedagógico. Em Aberto, Brasília, v. 17, n.72, p.35-46, fev./jun. 2000 .

CALVO PONTÓN, B. La Modernización educativa: una perspectiva regional desde la frontera norte de México. Ciudad de México, 1997. Tesis (doct.) Universidad Iberoamericana.

CALVO PONTÓN, B. et al. La Supervisión escolar de la educación primaria en México: prácticas, desafíos y reformas. Paris: lipe/Unesco, 2002.

CAMACHO, S. S. Modernización educativa en México, 1982-1998: el caso de Aguascalientes. Aguascalientes: Universidad Autónoma de Aguascalientes, Instituto de Educación, s.d.

Resistencia sindical a la descentralización educativa: el caso de Aguascalientes,

1978-1 993. Caleidoscopio. Aguascalientes: Universidad Autónoma de Aguascalientes, n. 7 , p.7-48, ene./jun. 2000.

CARDOSO, J. Gestão compartilhada da educação: a experiência catarinense. Revista Brasileira de Estudos Pedagógicos, Brasília, v. 76, n. I82/I83, p. I39-170, ago. 1995.

CARMONA, A. L. Proceso de desconcentración de la educación básica en el Distrito Federal. Ciudad de México, 1996. Tesis (doct.) Faculdad de Ciencias Políticas y Sociales, Universidad Nacional Autónoma de México.

CARNOY, M. National Voucher Plans in Chile and Sweeden: did privatization reforms make for better education? Comparative Education Review, Chicago, v.42, n.3, p.309-337, aug. 1998.

CASTRO, J. A. Federalismo e gasto público. Revista Brasileira de Estudos Pedagógicos, Brasília, v.79, n.192, p.92-100, maio/ago. 1998.

Gastos públicos com a educação básica. Revista Brasileira de Estudos Pedagógicos, Brasília, v.79, n. 193, p. I13-134, set./dez. 1998a.

CASTRO, M. L. S. A Gestão da escola básica: conhecimento e reflexão sobre a prática cotidiana da diretora de escola municipal. Em Aberto, Brasília, v. 17, n.72, p.71-87, fev./jun. 2000. 
CHILE. Ministerio de la Educación. La Escuela busca el compromiso de los padres. Revista de Educación, Santiago, n.284, mayo 2001.

COSTA, V. L. C. et al. Gestão educacional e descentralização novos padrões. São Paulo: Cortez, 1997.

CRUZ, S. H. V.; MAIA, M. H.; VIEIRA, S. L. Eleição de diretores: uma mudança na cultura escolar. Revista Brasileira de Política e Administração da Educação, Porto Alegre, v. I 5, n.2, p. 193-203, jul./dez. 1999.

DAVIES, N. O Fundef e o orçamento da educação: desvendando a caixa preta. Campinas, Autores Associados, 1999.

DÍAZ, Á. B. Los Procesos de frustración en la tarea docente. Revista Docencia, Santiago, Colegio de Professores de Chile, v. 17, n. 17, p.64-76, ago. 2002.

DONOSO DÍAZ, S. Balance y perspectivas de quince años de política y reforma educativa en Chile. Santiago, 2004. (mimeo)

DUSCHATZKY, S. (coord.) Aproximaciones al proceso de reforma en el tercer ciclo de la Provincia de la Pampa. Buenos Aires: Faculdad Latinoamericana de Ciencias Sociales, 1999.

DUSCHATZKY, S.; REDONDO, P. El Plan social educativo o los indicios de ruptura de las políticas públicas. In: DUSCHATZKY, S. (comp.) Tutelados y asistidos. programas sociales, políticas públicas y subjetividad. Buenos Aires: Paidós, 2000.

ESCOFFIER, M. T. Esos quatro milhones de pobres: la educación significa inversion social. Revista de Educación, Santiago, Mineduc, v. 7, n.224, p., mar. 1995.

ESPINOZA, J. J. Desarrollo y gestión educativa. Revista Economía y Administración, Santiago, Cpeip, Faculdade de Ciencias Económicas y Administrativas, Universidad de Chile, n. I 32 , p.65-75, ene./mar. 1997.

ESPINOZA, V. A. V. (coord.) Modernización educativa y cambio institucional en el Norte de México. Baja California: El Colegio de la Frontera Norte, 1999.

ESQUIVEL, G. H. Educación y desarrollo regional: una evaluación de aportaciones para la educación básica y normal. Momento Económico, Ciudad de México, n. I04, p. I3-20, jul./ ago. 1999.

EZPELETA, J. Cambio pedagógico sin cambio institucional en la escuela primaria: a propósito de la innovación. memoria eletrónica. Ciudad de México: Comie, out. 2003. [Ponencia a $7^{\circ}$ Congreso Nacional de Investigación Educativa]

Reforma educativa y zonas de turbulência. Ciudad de México: DIE, Cinvestav, 1997. 
EZPELETA, J.; WEISS, E. Cambiar la escuela rural. Ciudad de México: DIE, Cinvestav, 2000. FERNANDES, M. D. E. Política educacional: a gestão democrática na rede estadual de ensino em Mato Grosso do Sul (199I a 1994). São Paulo: Fundação Carlos Chagas, 1997.

FIGUEROA, A. R. Da resignação ao consentimento: privatização da educação média no Chile. Cadernos de Pesquisa, São Paulo, n. 100, p.49-56, mar. 1997.

FIORINI FILHO, J. A. Gestão da escola pública: o diretor em sua ação cotidiana. São Paulo, 1996. Dissert. (mestr.) Faculdade de Educação, Pontifícia Universidade Católica de São Paulo.

FONSECA, J. P. Poder local e municipalização: em busca da utopia; um estudo do município de Jacuí (MG). São Paulo, 1995. Tese (livre-doc.) Faculdade de Educação, Universidade de São Paulo.

FONSECA, M. A Participação escolar no contexto do PDE. In: (coord.) Novos modelos de gestão da educação básica: o que mudou na escola? Brasília: UnB, 2003.

FRACALANZA, P. S. A Gestão do ensino fundamental pelo governo do Estado de São Paulo: uma análise do financiamento e dos indicadores sociais de educação (1980-1993). Educação e Sociedade, Campinas, v.20, n.69, p.92-1 18, dez. 1999.

GARCÍA, R. M. M. (coord.); ROMERO, J. L. C. El Programa Escuelas de Calidad en la educación primaria. San Luis de Potosí: Secretaría de Educación del Gobierno del Estado, Coordenación General de Avaliación, 2003.

GARCÍA-HUIDORO, J. E. La Equidad y la igualdad en la educación chilena: comentários al capítulo 7 de revisión de políticas nacionales de educación. Santiago: OCDE; Universidad Alberto Hurtado, 2004. (ed.) La Reforma educacional chilena. Madrid: Popular, 1999.

GARCÍA-HUIDORO, J. E.; COX, C. Visión de conjunto. In: GARCÍA-HUIDORO, J. E. (ed.) La Reforma educacional chilena. Madrid: Popular, 1999.

GLUZ, N. Análise de los proyectos destinados a desarrollar nuevos lineamientos de política: equidad, consenso federal y modernización de la función pública 1993-1999. [Informe parcial para el Proyecto Alcance y Resultados de las Reformas Educativas en Argentina, Chile y Uruguai. Ministerios de la Educación de Argentina, Chile y Uruguai, Grupo Asesor de la Universidad de Standford, 200 I] (Relatório Brunner)

GOMES, A. A. J. Municipalização do ensino: da falácia utópica ao realismo competente. Tecnologia Educacional, Rio de Janeiro, v. 24. n. I22, p.7-। I, jan./fev. 1995.

GONÇALVES, R. O Financiamento da educação: um sistema em desequilíbrio. Cadernos de Pesquisa, São Paulo, n. 103, p. |4-15, mar. 1998. 
GONZÁLEZ, P. Financiamiento, incentivos y reforma educacional. In: GARCÍA-HUIDORO, J. E. (ed.) La Reforma educacional chilena. Madrid: Popular, 1999. p.23-26.

GONZÁLEZ, S. N. de S.; ARANGO, A. Educación en Argentina: icentralizando la descentralizatión y reformando la reforma? Revista Brasileira de Política e Administração da Educação, São Bernardo do Campo, v. I3, n. I , p.7I-106, jan./jun. 1997.

GUBBINS, V. F. Relación entre escuelas y familias: estado presente y desafios pendientes. Estudios Sociales, Provincia de Antofagasta: Faculdad de Educación y Ciencias Humanas, Universidad de Antofagasta, n. I08, 2001.

GUIMARÃES, J. Alguns impactos do Fundef: apontamentos e incertezas após a sua implantação. In: MARTINS, Â. M.; OLIVEIRA, C. de; BUENO, M. S. S. (org.) Descentralização do Estado e municipalização do ensino: problemas e perspectivas. Rio de Janeiro, DP\&A, 2004. p. $193-210$.

HERNÁNDEZ, G. E. Educación y desarrollo regional: una evaluación de aportaciones para la educación básica y normal. Momento Económico, Ciudad de México, n. I04, p. I3-20, jul./ago. 1999.

HERRERA, R. Reforma educacional: jornada escolar completa diurna. Santiago: Colegio de Professores de Chile, dic. 1996.

ILLANES, M. C.; LAGOS, M. Reforma educacional: a proposito de una encuesta. Revista de Educación, Santiago: Mineduc, n.260, p.42-48, 1998.

JACOBI, P. Educação, ampliação da cidadania e participação. Educação e Pesquisa, São Paulo, v.26, n.2, p. I I-29, jul./dez. 2000.

KESSLER, G. La Experiencia educativa fragmentada: estudiantes y profesores en las escuelas medias de Buenos Aires. Buenos Aires: lipe; Unesco, 2002.

KISILEVSKY, M. Federalismo y educación: un espacio historico de pugnas distributivas. Buenos Aires, s.d. Disert. (maest.) Faculdad Latinoamericana de Ciencias Sociales.

KRAWCZYK, N. R.; VIEIRA, V. L. O Estado da arte das pesquisas sobre a reforma educacional na década de 90, na Argentina, Brasil, Chile e México. São Paulo: Fapesp, 2005. (Relatório final)

KRICHESKYE, M.; CAPPELLARCCI, I. Gestión curricular y riesgo pedagógico en EGB3: un análisis de casos en Lomas de Zamora y La Matanza. Propuesta Educativa, Buenos Aires: Flacso, n.21, p.66-79, dic. 1999.

LATAPÍ, P.; HERRERO, M. U. El Financiamiento de la educación básica en el marco del federalismo. Ciudad de México: Centro de Estudios sobre la Universidad de la Unam, 2000. (Seção de Obras de Educación y Pedagogia) 
LAVIA, J. Gestión educaciona/ descentralizada: análisis y propuestas de acción a nivel municipal. Concepción: Universidad San Sebastián, 2002.

LAVIA, J.; SALAS, E. M. Gestión educacional descentralizada: análisis y propuestas de acción a nivel municipal. Concepción: Universidad San Sebastián, Chile, 2002.

LOERA, A. V. Reporte descriptivo de la línea de base de la evaluación cualitativa del Programa Escuelas de Calidad. Secretaría de Educación Pública, Subsecretaría de Educación Básica y Normal. Ciudad de México: Heurística Educativa, oct. 2003.

LOERA, A. V.; SANDOVAL, F. S. La Innovación en el processo de descentralización en el estado de Chihuahua. In: PARDO, M. del C. (coord.) Federalización e innovación educativa en México. Ciudad de México: El Colegio de México, 1999.

LÓPEZ, F. M. (coord.) Evaluación del programa de investigación y innovación. La Gestión en la Escuela Primária. Ciudad de México: Universidad Pedagógica Nacional, 2003.

LOYO, A.; MUÑOZ, A. La Concertación de las políticas educacionais. el caso de México. Ciudad de México: Instituto de Investigaciones Sociales de la Unam, Universidad Iberoamericana, 200I. (Documento de trabajo)

MARTINS, Â. M. O Processo de municipalização no Estado de São Paulo: um novo desenho da política educacional. In: MARTINS, Â. M.;OLIVEIRA, C.; BUENO, M. S. S. (org.) Descentralização do Estado e municipalização do ensino: problemas e perspectivas. Rio de Janeiro, DP\&A, 2004. p. $|5|-177$.

MATTOS, L. A. F. Democracia e colegiado de escola: qual democracia? Um estudo da gestão colegiada em Minas Gerais. Rio de Janeiro, 1998. Tese (dout.) Faculdade de Educação, Universidade Federal do Rio de Janeiro.

MELO, M. T. L. Gestão educacional: os desafios do cotidiano escolar. In: FERREIRA, N. S. (org.). Gestão da educação, impasses, perspectivas e compromissos. São Paulo: Cortez, 200 I. p. 243-254.

MENDONÇA, E. F. A Gestão democrática nos sistemas de ensino brasileiros. a intenção e o gesto. In: REUNIÃO ANUAL DA ANPED, 23. Caxambu, 24-28 set. 2000.

MERCADO, R. M. La Educación primária gratuita, una lucha popular cotidiana. Ciudad de México: DIE; Cinvestav, 1997. (Série Tesis)

MIZALA, A.; ROMAGUERA, P. Desempeño escolar y elección de colegios. la experiencia chilena. Santiago: Centro de Economía Aplicada, Departamento de Engieniería Industrial, Faculdad de Ciencias Físicas y Matemáticas, UCL, jul. 1998. (Documento de trabajo, 38)

Sistemas de incentivos en educación y la experiência del Sned en Chile.

Santiago: Centro de Economía Aplicada, UCL, 2000. (Documento de trabajo, 82) 
MIZALA, A.; ROMAGUERA, P.; FAREEN, D. Eficiencia tecnica de los establecimientos educacionales en Chile. Santiago: Centro de Economía Aplicada, Departamiento de Ingenería Industrial, Faculdad de Ciencias Fisicas y Matemáticas, Universidad de Chile, jul. I 998. (Serie Economía, 38)

NARCISO, P. B. Pariente pobre de las estratégias educativas. todo para el pueblo, pero sin el pueblo. Santiago, 1997. Disert. (maest.) Faculdad de Educación, Universidad de Chile.

NAVARRO, L. N. La Autoevaluación como herramienta para el controly mejoramiento de la gestión de los establecimentos municipales de educación. Santiago, 2000. Disert. (maes.) Faculdad de Educación, Universidad Católica de Chile.

NEVES, L. M. V. Um caminhar para um mesmo lugar. In: LESBAUPIN, I. (org.). O Desmonte da nação: balanço do governo FHC. Petrópolis: Vozes, 1999. p. 134- 135.

NúÑEZ, I. P. Antecedentes históricos de la actual renovación pedagógica en la educación chilena. Santiago, 1999. (mimeo)

Modernizaciones en la educación chilena en sig/o XX. Santiago, nov. 1994.

[Apresentada em sessão de la Sociedad Chilena de Historia de Educación]

Peculiaridad de la reforma chilena. Santiago, nov. 1999a. (mimeo)

La Politica educacional del régimen militar. Santiago, nov. 1999b. (mimeo)

OLIVEIRA, C. Algumas observações sobre o financiamento do ensino. In: MARTINS, Â. M.; OLIVEIRA, C.; BUENO, M. S. S. (org.) Descentralização do Estado e municipalização do ensino: problemas e perspectivas. Rio de Janeiro, DP\&A, 2004. p. I29- 143

OLIVEIRA, D. A.; DUARTE, M. R. T. Políticas e administração da educação: um estudo de algumas reformas recentes implementadas no Estado de Minas Gerais. Educação e Sociedade. Campinas, n.58, p.123-141, jul. 1997.

Politica e trabalho na escola: administração dos sistemas públicos de educação básica. Belo Horizonte, Autêntica, 1999.

OLIVEIRA, M. A. M. Qualidade, parceria e redenção: o projeto-piloto de implantação da qualidade total em uma escola estadual de Belo Horizonte. Campinas, 1997. Tese (dout.) Faculdade de Educação da Universidade Estadual de Campinas.

OLIVEIRA, N. C. M. A Política educacional no cotidiano escolar. um estudo meso-analítico da organização escolar em Belém-PA. São Paulo, 2000. Tese (dout.) Pontifícia Universidade Católica de São Paulo.

ORNELAS, C. (coord.) Valores, calidad y educación: memoria del primer encuentro internacional de educación. México: Santillana, 2002. 
OYOLA, C. (dir.) Innovaciones educativas. entre las politicas publicas y la practica educativa; un análisis de la reforma educativa del nivel médio en Rio Negro ( 1986-1996). Buenos Aires: Miño y Dávila, 1998.

PARDO, M. (coord.) Federalización e innovación educativa en México. Ciudad de México: El Colegio de México, 1999.

PARO, V. Eleição de diretores de escolas públicas: avanços e limites da prática. Revista Brasileira de Estudos Pedagógicos, Brasília, v.77, n. 186, p.376-395, maio/ago. 1996.

PAVAN, R. A Municipalização do ensino fundamental: o caso de Santos e Jundiaí. São Paulo, 1998. Dissert. (mestr.) Programa História e Filosofia da Educação da Pontifícia Universidade Católica de São Paulo.

PEREIRA, S. P. Disposición de los docentes de la comuna de La Granja frente a los ámbitos de la Reforma chilena. Santiago, 2000. Disert. (maest.) Faculdad de Filosofia e Educación, Universidad Metropolitana de Ciencias de la Educación.

PITHAN, N. de A. O Cotidiano escolar e o conselho de classe: uma abordagem simbólica e ritual. Rio de Janeiro, 1995. Dissert. (mestr.) Faculdade de Educação da Universidade Federal do Rio de Janeiro.

POBLETE, B. S. Participación y eficacia en la escuela: estudios empiricos. Santiago, 1996. Disert. (maest.) Faculdad de Educación, Universidad de Chile.

POLIAK, N. Reconfiguraciones recientes en la educación media: escuelas y profesores en una geografía fragmentada. In: TIRAMONTI, G. La Trama de la desigualdad educativa: mutaciones recientes en la escuela media. Buenos Aires: Manantial, 2004. p. I 47- 195.

PRADO, M. N.; GAJARDO, M. Educación rural: emergiendo desde lo propio; qué poco sabíamos de la escuela rural. Revista de Educación, Santiago, n.227, p.9-12, 1995.

PUIGGRÓS, A. Sujetos, disciplina y currículo en los orígenes del sistema educativo argentino. Buenos Aires: Galerna, 1990.

QUIRÓS, R. Las Condiciones de posibilidad de aprendizaje de los adolescentes en la educación secundária. Ciudad de México, 2000. Tesis (doct.) DIE-Cinvestav.

RECA, I. La Participación organizada de los padres en la educación. Revista Cuadernos Sociológicos, Santiago, Arcis Ediciones, n. I , 2002. (Resultados das Reformas Educativas na Argentina, Chile e Uruguai.)

RIQUELME, G. La Educación sencundaria antes y después de la reforma: efectos distributivos del gasto público. Buenos Aires: Miño y Dávila, 2004.

RIVAS, A. Gobernar la educación: estudio comparado sobre el poder y la educación en las provincias argentinas. Buenos Aires: Granica, 2004 
ROCKWELL, E. Escuelas comunitárias: una primera alternativa para el medio rural. Revista Colombiana de Educación, Santa Fe de Bogotá, n.34, p.38-47, $1^{\circ}$ sem. 1997.

ROMAGNOLI, M. C. et al. La Implementación del octavo año de la EGB en la Provincia de Mendoza. Mendoza, 2002.

SAN MIGUEL, J. Programa de Educación Básica Rural. In: GARCÍA-HUIDORO, J. E. (ed.) La Reforma educacional chilena. Madrid: Popular, 1999.

SANDOVAL, E. F. La Trama de la escuela secundária, instituições, relaciones e saberes. Ciudad de México: Universidad Pedagógica Nacional, Plaza y Valdés, 2002.

SCHIMIDT, W. A Municipalização do ensino fundamental em dois pequenos municípios rurais de Santa Catarina: Anitápolis e Santa Rosa de Lima (1987-95). São Paulo, 2000. Tese (dout.) Pontifícia Universidade Católica de São Paulo.

SCHMELKES, S. Problemas y retos de la educación básica en México. In: SIERRA, M. T. (coord.) Cambio estructural y modernización educativa. Ciudad de México: UPN, UAM, Comecso, 1995.

SERRANO, C.; FERNÁNDEZ, I. Antecedentes teóricos y históricos sobre el processo de descentralización educativa en Chile. Revista Estudios Sociales, Santiago, Corporación de Promoción Universitária, n. 107, jan./jun.2001.

SILVA, A. A. Contornos da gestão do ensino fundamental em Feira de Santana ( 1985- 1996). Rio de Janeiro, 200I.

SOUZA, R. de C. V. M. A Gestão do sistema público de ensino do Distrito Federal no período de 1995 a 1998: uma gestão praxística e multirreferenciada? Rio de Janeiro: Anped, 2001 .

SOUSA, S. Z. L. Parceria escola-empresa no Estado de São Paulo: mapeamento e caracterização. Educação e Sociedade, Campinas, v.21, n.70, p. I7| - | 88, abr.2000.

STREET, S. Modernización administrativa o democratización sindical: nuevas jerarquías o nuevos sujetos como vías de reforma educativa. In: EDUCACIÓN Y REFORMA CONSTITUCIONAL. Ciudad de México: Grupo Parlamentario del PRD, 200 I . p. I 85- 169. (mimeo)

TAPIA, F. M. Descentralización y calidad de los aprendizajes en escuelas municipales chilenas. Santiago, 1999. Disert. (maest.) Faculdad de Educación da Pontifícia Universidad Católica do Chile.

TEDESCO, J. C. Educación y sociedad en Argentina (1800-1900). Buenos Aires: Centro Editor de América Latina, 1982. (Série complementar: Educación y Cultura.)

TEDESCO, J. C.; TENTI FANFANI, E. La Reforma educativa en la Argentina: semejanzas y particularidades. Buenos Aires: lipe, nov. 200I. 
TEIXEIRA, L. H. G. Cultura organizacional e projeto de mudança em escolas públicas: um estudo de escolas da rede estadual de Minas Gerais. Campinas, 1998. Tese (dout.) Faculdade de Educação, Universidade Estadual de Campinas,.

TIRAMONTI, G. La Fragmentación educativa y los cambios en los factores de estratificación. In: La Trama de la desigualdad educativa: mutaciones recientes en la escuela media. Buenos Aires: Manantial, 2004. p. I 5-45.

Modernización educativa de los '90: iel fin de la ilusión emancipadora? Buenos Aires: Flacso, Temas, 2001.

TIZNADO, L. de los Á. M. La Reforma educativa chilena bajo la percepción del profesor de aula. Santiago, 2000. Disert. (maest.) Faculdad de Filosofia e Educación, Universidad Metropolitana de Ciencias de la Educación.

TORRES, Á.; GARSKE, L. M. Diretores de escola: o desacerto com a democracia. Em Aberto, Brasília, v. 17, n.72, p. I13-124, fev./jun.2000.

VAINI, S. S. Parceria, os perigos da educação (com)partilhada: a influência da iniciativa privada no currículo de escola pública municipal de São Paulo. São Paulo, 1999. Dissert. (mestr.) Pontifícia Universidade Católica de São Paulo.

VARGAS, P.; VARGAS, H. El Financiamiento compartido y la calidad de la educación. Mensaje. Santiago, Impresión Salesiana, v.46, n.445, p.6I-63, set. 1997.

VILLEGAS, C. P. La Descentralización de la administración pública: el processo de municipalización democratica del sistema educacional chileno. Santiago, 1999. Disert. (maest.) Universidad Académica de Humanismo Cristiano.

VIOR, S. (dir.) Estado y educación en las provincias. Buenos Aires: Miño y Dávila, 1999.

VIRIATO, E. O. Política educacional do Estado de São Paulo (95 a 98): desconstrução da escola pública. São Paulo, 200 I. Tese (dout.) Pontifícia Universidade Católica de São Paulo.

WEINBERG, G. Modelos educacionais no desenvolvimento histórico da América Latina. In: SAVIANI, D. et al. Desenvo/vimento e educação na América Latina. São Paulo: Cortez, 1987. p. 17-45. (Polêmicas do nosso tempo)

YEPES, L. D. C. Políticas educacionales para grupos vulnerables. lecciones de la experiencia chilena. Santiago, 2000. Tesis (doct.) Faculdad de Ciencias Físicas e Matemáticas, Universidad de Chile.

Recebido em: fevereiro 2006

Aprovado para publicação em: junho 2006 